\title{
Notas sobre a Solidariedade e o Fenômeno da Orfandade na Sociedade Akan-Agni Morofoé Da Costa Do Marfim (África Do Oeste)
}

Notes on Solidarity and Orphans in the Akan-Agni Morofoé Society of Ivory Coast (Western Africa)

Acácio Sidinei Almeida Santos

Doutor em Sociologia pela Universidade de São Paulo, pesquisador da Casa das Áfricas.

E-mail: acacioalmeidaœgmail.com

\section{Resumo}

Neste artigo propõe-se analisar as possíveis relações existentes entre o código de família marfinense, implantado em 1964, o fenômeno da orfandade e a crise da solidariedade comunitária vivenciada por parte da sociedade Akan-Agni Morofoé da Costa do Marfim. Acontecimentos importantes apontam para o fato de que o conjunto de leis promulgadas em 1964, ao ignorar as instituições tradicionais, ignorou também o fato de que os direitos costumeiros, além de milenares, são fontes de equilíbrio social, econômico e político. A análise, baseada em dados de realidade de duas aldeias, coloca em destaque os conflitos e controvérsias nascidos com a adoção de um código de família de inspiração ocidental, fato duramente sentido com o avanço da epidemia do HIV/AIDS.

Palavras-chave: Solidariedade; Orfandade; Akan-Agni Morofoé; Costa do Marfim; HIV/AIDS. 


\section{Abstract}

The purpose of this article is to analyze the possible relations between the family code in Ivory Coast, implanted in 1964, the orphan phenomenon and the community solidarity crises lived by part of AkanAgni Morofoé society. Some important facts that happened after the 1964 laws, that ignored traditional institutions, also ignored millenaries costumier rights that are the basis of a social, economic and political equilibrium. The analysis, based on reality data of two villages, highlights the conflicts and controversies originated by the adoption of the occident inspired family code, fact maximized by the growth of HIV/AIDS epidemic.

Keywords: Solidarity; Orphan; Akan-agni Morofoé, Ivory Coast; HIV/AIDS.

\section{Introdução}

A primeira motivação para o desenvolvimento desse tema nasceu de nossas experiências de pesquisa na Costa do Marfim (África do Oeste), durante o doutorado, mais especificamente no trabalho de campo desenvolvido nos anos de 2000 e 2002. Ainda na elaboração da tese de doutorado intitulada "Os Akan-Agni Morofé da Costa do Marfim (África do Oeste) frente à emergência e à disseminação do HIV/AIDS" fizemos algumas notas a respeito das questões que envolviam a solidariedade e a orfandade na região do N’Zi-Comoé, aldeias Ande e Kouassikro, lugar de nossas pesquisas, e é baseado nelas que escrevemos.

A convivência com os Agni Morofoé, no momento em que a Costa do Marfim passa por uma de suas mais graves crises políticas, nos coloca diante do desafio de compreender as transformações sociais em curso e os impactos ocasionados por essas mudanças nas redes de solidariedade comunitária. Para a realidade de um país duramente atingido pela AIDS, no centro do debate encontra-se o desenvolvimento do capitalismo, questão amplamente estudada por Samir Amin (AMIN, 1967), e a adoção, no período pós-independência, de um código de família fundado sobre normas próprias da família moderna do ocidente industrializado.

O novo código, em consonância com o projeto desenvolvimentista, fazia parte das tentativas do governo marfinense de suprimir as relações tradicionais, entendidas como entraves no nascimento e desenvolvimento de uma sociedade industrializada e também no processo de construção da nação. Em outras palavras, tratava-se de suprimir a diversidade de costumes locais dos sessenta grupos étnicos que, baseados no direito costumeiro, regulavam as relações de poder e de solidariedade comunitária no interior de cada uma das sociedades.

Esses são, a nosso ver, elementos importantes na compreensão do fenômeno da orfandade e da crise da solidariedade comunitária vivida pelos Agni Morofoé, subgrupo do grupo Akan. 


\section{Esquecer a Tradição, Buscar a Modernidade}

Em agosto de 1966, durante os festejos do $6^{\circ}$ aniversário de independência da Costa do Marfim, o então presidente Félix Houphouët-Boigny, em um de seus habituais discursos, reafirmava a vocação do país para a modernidade dizendo:

Quando percebemos que a sobrevivência de certas tradições era um obstáculo ou um freio à evolução harmoniosa de nosso país, nós não hesitamos em realizar as mudanças necessárias. Foi assim que, após uma longa campanha de explicações feita por nossos militantes e nossos representantes políticos e administrativos junto às populações, sobre as questões importantes, chegou o dia. Um código civil renovado, consagrado à supressão da poligamia e do dote foi colocado em prática; um código civil moderno. (HouphouëtBoigny, 1978, p. 742-743)

O presidente Houphouët-Boigny tratava em seu memorável discurso de expor os rumos da nação recentemente criada, fazendo referência direta ao novo código civil e às leis 375 (relativa ao casamento civil) e 379 de 1964 (relativa às sucessões e heranças), que atingiam de forma direta a organização familiar e sua estruturação.

Em outras palavras, entrava em cena a família nuclear, entendida como o modelo mais adequado aos elementos constitutivos da modernidade: monetarização das relações de produção e das relações sociais, autonomia dos agentes econômicos, mobilidade social e espacial dos trabalhadores etc.

A lei $n^{0} 375 / 64$, além de tratar das questões comuns a outros códigos civis (obrigações recíprocas, fidelidade etc.), também tratava do estabelecimento de um regime único de comunhão de bens entre os cônjuges (art. 74), embora outorgando exclusivamente ao marido a chefia da família e a responsabilidade de administrador legítimo dos bens comuns e dos bens pessoais do casal. À mulher, coadjuvante na relação, a lei garantia o direito de substituir o marido no exercício da chefia, desde que este estivesse impedido de mani- festar sua vontade, por razões de incapacidade, ausência ou qualquer outra causa (art. 58). Além disso, a lei também estabeleceu que os cônjuges deveriam viver juntos, sob o mesmo teto, e deu ao homem plenos poderes para a escolha do local.

Ainda que do ponto de vista legal, com a adoação do modelo de comunhão de bens, parecese existir uma preocupação central com a preservação dos direitos da mulher ${ }^{1}$ em relação à propriedade, é consenso entre pesquisadores (Marie, 2002) que o "ponto alto" do conjunto de leis promulgadas em 1964 foi a radical medida referente à proibição da poligamia. Assim, a partir de 1964, apenas as relações poligâmicas já pactuadas antes da promulgação da lei eram "reconhecidas", embora a sua dissolução não autorizasse a realização de novos pactos. Em outras palavras, a crença do legislador era que ao longo de algumas décadas desapareceriam as instituições poligâmicas e, com elas, o "atraso" do qual padecia a Costa do Marfim.

Promulgada a lei, somente o casamento civil passou a ser reconhecido pelo Estado marfinense como legal e o único capaz de criar a legítima e verdadeira família (art. 50).

Em o2 de agosto de 1983, com o objetivo de reformar e adaptar a lei $n^{0} 375 / 64$, entra em vigor a lei $n^{0}$ 80o/83. Aspectos importantes dessa nova lei são a liberdade que passa a ter o casal na escolha do regime do casamento (comunhão total ou parcial de bens) no ato do pacto nupcial ou depois dele, o direito da mulher de exercer uma profissão e o poder de decidir sobre os produtos do seu trabalho.

Passados 40 anos desde a promulgação da lei ${ }^{0}$ 375/64, notamos que, entre a tradição e a modernidade, multiplicam-se os exemplos da diversidade de estruturas familiares existentes na Costa do Marfim, revelando as adaptações nascidas nas brechas da lei e confirmando aquilo que já assinalava Éliette Abitbol em 1964:

As reformas não serão sem riscos. É difícil regulamentar através de leis as relações familiares, sobretudo quando isso significa uma grande mudança das instituições preexistentes. A oposição que pode provocar

\footnotetext{
1 Para Folquet, o legislador, ao impor o regime de comunhão de bens, garantiu às mulheres direitos sob a propriedade na dissolução do casamento. Isso porque, embora na maior parte das sociedades marfinenses, segundo o direito costumeiro, exista uma separação dos bens da mulher e do marido durante o casamento, no divórcio as mulheres costumam deixar a relação sem direito a qualquer bem.(Folquet, 1974)
} 
a intromissão do Estado em um domínio que lhe escapa totalmente, é impossível de prever as reações sociais que suscitará o novo sistema e as desordens que ele pode engendrar. (Abitbol, 1966, p.305)

O conjunto de leis promulgadas em 1964, além de ignorar as instituições tradicionais das diferentes sociedades e grupos étnicos, ignorou também o fato de que os direitos costumeiros, além de milenares, são fontes de equilíbrio social, econômico e político, e que a tentativa de seu desmantelamento poderia levar a conseqüências desastrosas.

O novo modelo, com forte inspiração patriarcal, ignorou o fato de que nas sociedades matrilineares, como afirma Fábio Leite, "as mulheres constituem fontes de legitimação na medida em que apenas elas fazem configurar as descendências e as posições dos indivíduos na estrutura da família para fins de sucessão e conseqüente acesso ao poder." (Leite, 1991/1992, p. 110)

Por meio de uma leitura mais atenta da realidade podemos identificar pelo menos três diferentes esferas de comportamentos e atitudes que se deram como resposta ao novo modelo: a) a primeira, formada por um grupo inexpressivo, movido por interesses muito particulares que aceitou o novo modelo; b) a segunda, formada por um grupo que adaptou o novo modelo às suas necessidades e às leis originárias; c) a terceira, formada basicamente por tradicionistas ${ }^{2}$ da África profunda que recusaram totalmente o novo modelo.

Assim, nos últimos anos a Costa do Marfim, em razão de diversos fatores (crise do tutorado, monetarização das relações de produção e das relações sociais, emigrações e imigrações), tem experimentado sérias mudanças no que tange à constituição da família.

Como na sociedade Akan a família é o núcleo básico da organização social, sua desagregação afeta todo o sistema e interfere nos modelos básicos de conduta dos indivíduos, colocando em risco o desempenho pleno de certos papéis sociais ou as obrigações correspondentes a esses papéis.

As mudanças sugeridas e introduzidas na socie- dade marfinense e absorvidas forçosamente pelas comunidades rurais e urbanas, ao mesmo tempo em que cumprem as reais necessidades de implantação do modelo ocidental, sem o qual a proposta modernista naufragaria, extrai daquela sociedade os elementos da solidariedade comunitária e estabelece a lógica da dívida, fazendo dos pactos ancestrais simples contratos do tipo credor/devedor.

Entre a obrigatoriedade do Estado de um casamento segundo as leis modernas e a existência do padrão tradicional, surgem as uniões livres. 0 casamento passa a ser um ato individualizado e reduzido à vontade de duas pessoas e não mais de duas famílias. O Estado torna-se forte e a família, sem os pactos nupciais fundadores, se enfraquece nos seus atributos, principalmente nas questões de solidariedade que envolvem a reciprocidade e a acolhida.

Atualmente, essa realidade, para a qual a hospitalidade e a fraternidade estão ligadas à cultura e aos comportamentos morais, vem atravessando uma grave crise, com sérias implicações no campo das relações entre autóctones e estrangeiros, no campo das relações familiares e de linhagens e, no campo da solidariedade comunitária, ampliando ainda mais a exclusão social de uma crescente parcela da população. A novidade dos últimos tempos é aumento no número de crianças, mulheres e velhos que esmolam e dormem nas ruas de Abidjan.

Por isso acreditamos que a crise do tutorado não é apenas uma crise nas relações entre autóctones e estrangeiros ${ }^{3}$, é também uma crise entre membros de uma mesma família autóctone, entre gerações de uma mesma família autóctone e entre gerações de diferentes famílias, com sérias implicações nas relações de trocas e responsabilidades.

Os mais jovens, principalmente aqueles que estudaram e hoje são diplomados e não encontram trabalho na cidade, acusam os velhos aldeões de terem cedido aos estrangeiros significativas extensões de terras por meio do sistema de tutorado. A lógica é simples e serve para alimentar a xenofobia: a promessa desen-

\footnotetext{
20 termo tradicionista foi adotado, segundo Leite (1982), pelos participantes do Seminário sobre a "Civilização Senufo", realizado em Korhogo, Costa do Marfim, em agosto de 1979.

3 Estrangeiro é todo homem que vem de fora: ele pertence a um outro grupo humano cuja ideologia social é diferente. Esta situação é visivelmente observável pelo uso de uma língua estrangeira. A terra que ele ocupa temporariamente não é sua terra natal, seus ancestrais não estão sepultados nela. (Eschlimann, 1985, p.163)
} 
volvimentista pós-1964 torna-se cada vez mais excludente e os jovens, que tinham no campo uma saída possível, se vêem pressionados diante da escassez de terras produtivas nas aldeias e a falta de emprego nas cidades. Os estrangeiros e alguns membros da família extensa tornam-se "bodes expiatórios" de uma lógica perversa.

\section{Tutorado e Hospitalidade}

Na sua história, a Costa do Marfim sempre foi reconhecida como um país de hospitalidade e fraternidade, haja vista a existência de poderosas instituições costumeiras, cujo maior exemplo é o tutorado, que garantia a todos, inclusive aos estrangeiros, o acesso à terra, bem considerado inalienável.

A existência do tutorado, associada à necessidade de mão-de-obra para as culturas de exportação e o crescimento econômico da Costa do Marfim, nos anos que vão de 1960 a 1980, tem servido para explicar a forte presença estrangeira no país, principalmente de imigrantes originários do Burkina Faso, e o deslocamento interno de algumas populações para terras com potencial agrícola para as culturas cacaueira e cafeeira.

Como a relação entre populações autóctones e estrangeiras na ocupação e exploração da terra foram e continuam sendo - fontes de alguns problemas, ainda que os envolvidos estivessem sempre inclinados às soluções pacíficas, baseadas nos direitos costumeiros de cada sociedade, em 1958 os Agni Sanwi editaram um código fundiário com regras específicas sobre a concessão de terras para exploração agrícola de estrangeiros (D’Aby, 196o, p.174-175) afirmando que:

- Todo estrangeiro que recebe a hospitalidade na casa de um chefe tradicionista ou na casa de qualquer outra pessoa, na qualidade de hóspede, poderá obter deste o usufruto de uma parte da terra de direito da cadeira onde ele vive, por meio do pagamento exigido costumeiramente.

- Caso o estrangeiro faleça sem que tenha quitado os pagamentos exigidos, o chefe ou o seu tutor terá direito à plantação e aos frutos da terra explorada por ele e cujo usufruto lhe tinha sido concedido.

- Se o falecido tiver se casado com uma mulher da família que o hospedou, os bens poderão ser transferidos para a viúva ou para os seus filhos.
- Se um de seus parentes vier viver com ele e trabalhar na mesma família que o hospedou, terá direito à metade dos bens produzidos no campo, desde que esteja residindo na localidade sob a guarda daquela família há pelo menos seis meses.

- O chefe de linhagem e o rei podem autorizar que certos estrangeiros ocupem extensões definidas de terras em localidade Agni por tempo indeterminado ou por um período de nove meses.

- Antes do estabelecimento formal do contrato, o requerente deverá indicar por escrito a verdadeira destinação que dará à terra solicitada; deverá pagar os impostos da corte ou da coletividade local; deverá respeitar as obrigações para com os usos e costumes do reino, salvo naquilo que diz respeito à família e a sucessão, e não poderá alienar as plantações em favor de terceiros. (D’Aby, 1960)

O código fundiário Agni Sanwi, além de ser revelador do direito costumeiro que regula o acesso à terra por meio das cadeiras ancestrais e das relações entre autóctones e estrangeiros, também trata das questões da família e da sucessão, reconhecendo que o "hóspede", sendo um estrangeiro, possui seus próprios usos e costumes.

Assim, durante anos, ainda que alguns conflitos entre autóctones e estrangeiros envolvendo o acesso à terra fossem verificados, essas instituições serviram à manutenção da solidariedade comunitária (familiar, de linhagem e de aldeia), envolvendo autóctones e estrangeiros.

Parte das explicações para o tutorado está no fato de que os Akan, tendo imigrado para o território da atual Costa do Marfim no século XVIII, não se consideram os verdadeiros "senhores donos da terra", e só a ocupam por terem conseguido a devida autorização dos Boson (elementais da terra, dos rios, das florestas etc.) por meio de pactos propiciatórios.

A convulsão política e social, cujos exemplos mais memoráveis são o golpe de Estado ocorrido em dezembro de 1999 e a atual crise com a divisão do país em duas porções (norte e sul), é reveladora da grande desestabilidade vivida em setores importantes da Costa do Marfim. O golpe abriu novas feridas sociais e aprofundou outras já existentes, nascidas da crise econômica dos anos 1980 e agravadas pela epidemia do HIV/AIDS. 


\section{Anos 1980, Tempo de Crise}

Desde a sua independência, ocorrida em 196o, até a década de 1980, o crescimento econômico da Costa do Marfim foi tão vertiginoso que especialistas chegaram a compará-lo ao "milagre econômico" observado em alguns países do sudeste asiático, sobretudo Coréia do Sul e Taiwan.

Anos depois (1981-1983), a crise financeira internacional, somada aos problemas decorrentes da deterioração do mercado internacional do café e do cacau (os dois principais produtos de exportação da Costa do Marfim) e aos problemas da zona franca da CFA (Comunidade Financeira Africana), geraram dificuldades econômicas e sociais endêmicas que não foram até hoje totalmente solucionadas.

No mesmo período, os programas de ajustamento estrutural desenvolvidos e gerenciados pelo Banco Mundial fizeram reduzir as despesas públicas e o papel do Estado na economia nacional e, sob o argumento de que as empresas públicas eram além de improdutivas, propícias ao nepotismo e à corrupção, vários setores foram privatizados.

O reflexo dos projetos políticos de estabilização e de ajustamento estrutural foi sentido em todos os setores da vida socioeconômica do país, sobretudo na área da saúde, o que favoreceu, no caso do HIV/AIDS, o que Paul Farmer intitulou de economia política da epidemia. (Farmer, 1992)

A Costa do Marfim é hoje um país dividido política e territorialmente e, no campo da saúde, um país em transição epidemiológica onde persistem endemias antigas como a malária, o trypanosoma, a oncocercose, a lepra e a dracunculose (verme da Guiné); emergentes como o HIV/AIDS e a úlcera de Bauru e reemergentes como a tuberculose, ao mesmo tempo em que se desenvolvem as patologias ligadas aos novos hábitos de consumo (câncer, doenças cardiovasculares, diabete).

A rápida difusão do HIV/AIDS na Costa do Marfim e a amplitude dos desastres sociais que provocam podem ser estimados partindo-se das informações existentes sobre a soroprevalência no país. Pesquisas realizadas em diferentes regiões indicaram que no conjunto da população sexualmente ativa a taxa média de contaminação estava na casa dos 10\%. Por trás das estatísticas notamos que o impacto do HIV/AIDS se dá em esferas largamente incomensuráveis: sofrimen- tos, lutos, mudanças, perdas globais, criatividades interrompidas e gerações aniquiladas.

Nas sociedades agrícolas, o desaparecimento prematuro de uma geração, além de promover o crescimento de uma multidão de órfãos, rompe a transmissão de conhecimentos teóricos e práticos primordiais, colocando em grave situação a subsistência de populações inteiras.

E, como $70 \%$ da produção de víveres (agricultura de subsistência) da Costa do Marfim e a segurança alimentar, mantida por uma cadeia de atividades (produção, coleta, transporte, comercialização, armazenamento, conservação, transformação...) são assegurados pelas mulheres, quando uma mulher adulta adoece ou falece a segurança alimentar quase sempre entra em crise. (Baha, 2001)

Assim, a AIDS não traz apenas o problema do custo da doença. As conseqüências no âmbito das famílias são múltiplas, forçando-as a uma reorganização nas estruturas de produção. A epidemia tem conseqüências sobre o potencial de desenvolvimento dos grupos sociais e do país, uma vez que afeta mais diretamente as populações em idade fértil e aquelas mais importantes na produção social e econômica.

O peso do doente de AIDS no orçamento da família, analisado por Bechu, Delcroix e Guillaume em "Devenir socio-economique des enfants et familles affectes par le VIH/SIDA dans les pays en developpement : les cas de la Côte d'Ivoire", revela que a maior parte dos recursos domésticos consumidos com cuidados na área da saúde (consultas, medicamentos, tratamentos etc.) mais do que dobraram nos casos em que existem pessoas doentes de AIDS na residência: $10,6 \%$, contra 5,6\% nas outras residências. O Posto de saúde representa $80 \%$ das despesas de saúde específicas que tem o doente de AIDS, ou 8,4\% do consumo total. Em média, cada residência pesquisada gastou 91.66o FCFA com os cuidados do paciente HIV, um pouco mais de 5.70o FCFA por mês. (Bechu, et alii, 1997).

Nas aldeias Ande e Kouassikro é perceptível a sobrecarga nas células de consumo associada ao crescimento da epidemia e ao redirecionamento de crianças da cidade para o campo, em função do adoecimento ou da morte de um dos pais, enquanto a célula de produção se vê reduzida pelo mesmo problema.

A doença compromete o orçamento da família que tem que dispor de elevadas somas para o tratamento 
do indivíduo doente sem que ele possa contribuir com o grupo, gerando um desequilíbrio na direção do doente, o que significa dizer que ela passa a se apropriar de uma parcela maior das riquezas produzidas pelo grupo. E, à medida que a doença se agrava para o quadro terminal, maiores são as despesas. E, se os gastos com o doente aumentam, a família terá que buscar novos recursos ou mesmo diminuir os gastos com outras despesas, na garantia da continuidade de um tratamento. 0 momento posterior à descoberta da doença até o falecimento pode significar somas que ultrapassam $25 \%$ do orçamento familiar. (Bechu, et alii, 1997 , p.14) Com a morte, a família tem ainda um gasto suplementar com os funerais e posteriormente com as dívidas contraídas em função da doença e dos funerais.

\section{Aids e Orfandade}

Do ponto de vista qualitativo, os problemas de ordem econômica, jurídica e social que nascem com a morte de um ou dos dois genitores em virtude do HIV colocam os órfãos da AIDS numa situação muito diferenciada se comparada à dos outros órfãos, justamente pelo estigma da doença, o que faz com que essas crianças sejam recusadas pela família extensa, antiga acolhedora, e passem às instituições.

O estudo dos órfãos revela o impacto social e econômico desta epidemia e o quanto ela desorganiza as famílias e satura os sistemas costumeiros de cuidado, as redes de solidariedade que se tornam precárias frente à demanda.

Segundo Yenou, na Costa do Marfim "cerca de 10\% das crianças correm o risco de se tornarem órfãs de um de seus genitores em função da epidemia do HIV/ AIDS. Este alarmante número de órfãos muito provavelmente não poderá ser absorvido pela família extensa no atual estado das coisas." (Yenou, 2001 , p. 134) Isso significa dizer que as redes tradicionais de acolhida estão sobrecarregadas e já não conseguem absorver a demanda imposta pelas crises política, econômica e social. No momento da escolha, quando é possível escolher, a família sempre opta pelos filhos daqueles que se mantiveram na célula de produção, mesmo estando fora da aldeia.

Os estudos desenvolvidos na Costa do Marfim por Guillaume (1996) revelaram que a AIDS tem provocado sérias transformações na estrutura das famílias tocadas pela epidemia, e que a dissolução do casamento e/ou a morte do membro da família responsável pela maior contribuição material para o sustento da família tem propiciado uma precarização das condições econômicas, o que interfere diretamente no sustento e nos cuidados dos filhos. Os estudos de Barnett et Blaikie (1992) são particularmente importantes por mostrarem os graves impactos da epidemia sobre as famílias de modelo nuclear quando os dois genitores morrem.

Entretanto, o recente quadro da orfandade, amplamente divulgado quando se trata de discutir a epidemia do HIV/AIDS na África subsaariana, parece ignorar que as sociedades estabeleceram estruturas tradicionais de acolhida de crianças. Assim, ao afirmarmos que a hospitalidade e a solidariedade comunitária são elementos relevantes entre os Akan-Agni Morofoé, deveremos também afirmar que naquela sociedade a orfandade é uma anomalia combatida através da regras de sucessão e herança. Isso porque a noção de pertencimento é crucial no funcionamento harmônico da estrutura social Akan e as crianças representam a continuidade da vida.

Para uma melhor compreensão, passemos a algumas notas sobre os Akan-Agni Morofoé.

\section{Solidariedades}

A solidariedade e a orfandade na Costa do Marfim, a despeito da extrema complexidade de sua avaliação empírica, fazem parte de um fenômeno que, a nosso ver, só pode ser analisado a partir da singularidade e das peculiaridades históricas desse país da África do Oeste, sobretudo as questões ligadas ao seu desenvolvimento econômico, como apontamos acima.

Ainda que a solidariedade possa ter, em muitos casos, a lógica da dívida como um dos seus principais componentes, a reciprocidade é um princípio importante na manutenção das relações comunitárias, assegurando o presente e o futuro.

A lógica da dívida é reducionista à medida que vê nas relações apenas um tipo de contrato, como se alguns fossem credores e outros devedores, ajudar hoje para ser ajudado amanhã. Ela também é condenável à medida que a acumulação fere os princípios de redistribuição das sociedades Akan. Motivo pelo qual entre os Agni Morofoé as manifestações de solidarieda- 
de e doação são sempre realizadas publicamente nos nascimentos, casamentos, funerais e nas situações de doença.

Não é estranho aos membros da sociedade a idéia de que para obter a solidariedade e a justa proteção social do grupo (família, linhagem ou aldeia), devesse contribuir com cotas solidárias antes e depois. Se ele usar antes, deverá contribuir depois, alimentando as regras de reciprocidade no seio do grupo.

Neste sistema, assegurado também pela coerção, os Bayafoé (comedores de alma) e as práticas de bruxaria são extremamente importantes. Aqueles que foram beneficiados pelo grupo e esquecem-se das regras de reciprocidade ou aqueles que mesmo não tendo se beneficiado esquecem-se dos familiares são vítimas preferenciais.

Os problemas econômicos dos anos 1980 e 1990 colocaram em perigo as solidariedades comunitárias, fortalecendo as relações monetarizadas estabelecidas na lógica da dívida. Ela interfere na lógica da reciprocidade e compromete o regime de solidariedades entre famílias extensas, linhagens, aldeias e também entre diferentes comunidades e o próprio Estado. Está inaugurada a lei do "cada um por si e Deus por todos" e "salve-se quem puder".

A solidariedade comunitária é colocada em jogo ao mesmo tempo em que aumenta a escassez dos recursos disponíveis para a redistribuição comunitária. Entre os nossos entrevistados percebemos que alguns tentam se desligar das redes familiares quando detentores de algum recurso financeiro, embora a lógica ainda faça com que aqueles que estão empregados em particular os funcionários públicos - destinem uma parte dos seus salários para subvencionar a abertura de pequenos comércios (cabine telefônica, cabeleireiro, restaurante, atelier de costura) para empregar alguns parentes e ajudar na economia doméstica.

E se a relação passa a ser então entre credores e devedores, a solidariedade deixa de ser um valor moral e o não-pagamento das dívidas faz cessar os empréstimos aos "maus pagadores".

\section{Os Akan-Agni Morofoé da Costa do Marfim}

Sobre os Akan da Costa do Marfim, relatos históricos e míticos afirmam terem sido as dissensões ocorri- das no século XVII, envolvendo alguns subgrupos do grupo Akan (Ashanti, Agni e Baoulé), na região conhecida na atualidade como Gana, o real motivo para o grande deslocamento populacional ocorrido naquela região da África do Oeste, mais precisamente de Gana para a Costa do Marfim.

$\mathrm{Na}$ atualidade, segundo dados do último censo populacional da Costa do Marfim, realizado em 1998, os Akan representam $42 \%$ da população marfinense e são o maior grupo étnico daquele país, ocupando um território que se estende da fronteira leste, que divide a Costa do Marfim e Gana, onde os grupos Abron, Agni, Juabem, Essouma e Nzima; passando pelo centro do país onde está essencialmente o grupo Baule; até o sul onde estão os grupos Abe, Abidji, Aboure, Akye, Adiokrou, Avikan, Alladian, Ebrie, Ewotire e Ega. (Leite, 1982).

Matrilineares e patrilocais, cada aldeia Akan é liderada por um chefe local e o conjunto das aldeias, por um chefe de linhagem ou por um rei. Muito embora os chefes sejam política e administrativamente independentes, existe uma relação fortemente hierarquizada entre chefes de aldeia, chefes de cantão e os reis.

À terra (Assié), como origem da fecundidade, são dedicados grande parte dos rituais, sacrifícios e oferendas exigidos para o início do trabalho agrícola ou para o início de um novo ano agrícola, como é o caso da festa do inhame, uma das expressões máximas da conjunção entre o culto à terra e à fecundidade e o culto aos ancestrais.

Por isso, a terra não é para os Agni uma moeda de troca ou de barganha, nem tampouco uma riqueza em si mesma, a não ser pela interferência dos ancestrais, que ao torná-la fecunda possibilitam a sua exploração para a produção das mais diferentes riquezas, como a agricultura e a metalurgia.

Assim, um dos princípios essenciais entre os Agni é que todos que estejam ligados a uma cadeira ancestral (bya) têm acesso a terra, ou seja, têm direito de cultivar uma superfície suficiente para produção do alimento necessário à vida de sua família.

Todo indivíduo ou grupo que desejar se instalar sobre terras ainda não humanizadas deve dirigir-se aos elementais (boson) do lugar, solicitando autorização para a ocupação, o que normalmente é concedido sob a forma de um pacto consagrado pela oferenda e aceitação do sacrifício indicado. (D’Aby, 196o) 


\section{Pertenço, logo Existo}

A exemplo dos demais grupos da constelação Akan, a organização social Agni está baseada em unidades de descendência matrilinear (Malata), ou seja, o parentesco é determinado pela existência de um ancestral feminino comum. Assim, todas as crianças nascidas da mesma mãe, de duas irmãs uterinas ou de duas primas descendentes da mesma avó pertencem a um mesmo Malata e são consideradas Niama. Os ascendentes diretos do Niama são Ni, enquanto que os descendentes imediatos são M’ma. Já as crianças nascidas do mesmo pai ou de irmãs e primas do grupo paterno são chamadas Siema.

A residência $\left(\mathrm{Awlo}^{4}\right)$ é um nível privilegiado das relações entre o indivíduo e sua localidade, já que é por meio dela que o chefe de linhagem ou de família cumpre importantes funções sociais, representando a célula familiar nas assembléias da localidade, assistindo aos ritos coletivos etc. Isso só é possível porque os membros da célula familiar estão ligados a ele pelas relações de parentesco, de aliança ou mesmo de dependência. A comunidade de residência é, por assim dizer, o lugar privilegiado de referência dos indivíduos que são os verdadeiros suportes da célula de produção ou da comunidade econômica. (Gastellu, 1979)

Em Andé e Kouassikro encontramos o mesmo padrão costumeiro de ocupação de outras localidades Akan. Ela é formada por um conjunto de diferentes unidades de residência responsáveis pelas atividades essenciais à sobrevivência e à reprodução demográfica, econômica e social do grupo, além de também se responsabilizar pela produção, distribuição e consumo; socialização das crianças; culto aos ancestrais, transmissão dos saberes etc.

Entre os Agni, as unidades de residência e de consumo são também unidades de produção. Mesmo aqueles que não estão ligados à agricultura pertencem ao grupo por contribuírem monetariamente para a produção. A unidade de residência é também a unidade de reprodução demográfica. Este grupo é definido por status e atribuições bem definidos.

Além disso, a exemplo de outras sociedades negro- africanas, também entre os Agni é papel das unidades de residência, da família extensa e da sociedade em geral garantir todos os processos necessários à construção da individualidade, bem como os elementos necessários à edificação da personalidade e a realização da missão e do destino vital do indivíduo.

\section{Comunidade de Residência, Local de Solidariedades}

Na África do Oeste, uma organização econômica resulta, para uma sociedade particular, da combinação, por um lado, de um sistema de parentesco no qual os agentes sociais a ele ligados articulam modelos segundo seus interesses e as possibilidades oferecidas pelo próprio sistema, e, por outro lado, da ecologia, da história e das regras fundamentais concernentes à organização e à divisão da produção. (Gastellu, 1979)

Entre os Akan, o melhor posto de observação da organização econômica é a comunidade de residência. Nela, a reprodução econômica pode ser observada por meio de três unidades complementares: a unidade de produção, a unidade de consumo e a unidade de acumulação, como demonstraremos.

A unidade de produção, embora formada por diferentes pessoas, tem no centro de decisões apenas o Fiédifwé (chefe), nome atribuído àquele que é responsável por um espaço de produção, e é formada por duas células, uma doméstica e uma estrangeira. Enquanto a célula doméstica tem um papel familiar preciso e é definida pelas relações de parentesco, a célula estrangeira é definida simplesmente pela relação de trabalho que estabelece com os Agni e pelo status decorrente da sua condição étnica.

A célula doméstica representa ao mesmo tempo uma coletividade onde se executa em comum um certo número de atividades essenciais no domínio da reprodução demográfica, econômica e social, além de ter sob sua responsabilidade a produção de grande parte dos produtos destinados quase exclusivamente à alimentação. A célula estrangeira tem como único papel na sociedade Agni trabalhar nos campos de culturas perenes (café e cacau).

4 O Awlo é o termo Agni que designa o conjunto de casas ocupadas pelos membros de uma mesma família dentro de uma localidade. Cada família pode ocupar um ou mais Awlo. 
É por meio da unidade de consumo, que em muito se define pelo seu aspecto alimentar, que podemos notar o papel maior da unidade de produção, ou seja, produzir o suficiente à autoconsumação. Nela, percebemos também a solidariedade comunitária em torno do consumo dos alimentos e no atendimento das demais necessidades e urgências, como no caso de doenças e nos funerais.

Embora a idéia seja a de que cada família consome aquilo que ajudou a produzir, nem todos que consomem dentro da célula doméstica pertencem à unidade de produção. É o caso, por exemplo, das crianças, dos estudantes e dos velhos que já não podem trabalhar nos campos.

Na comunidade de residência de muitos dos nossos entrevistados, quando indagávamos a respeito da relação de parentesco das pessoas que dormiam e se alimentavam na residência, encontrávamos também as irmãs germânicas ou uterinas do chefe de família, os filhos dessas irmãs, além de outros agregados, todos eles parentes uterinos do chefe da célula doméstica.

A unidade de acumulação parte da idéia fundamental existente em muitas sociedades rurais africanas de que todo grupo de produção trabalha não somente para poder reconstituir a força de trabalho, mas também para ter uma reserva de bens que permita enfrentar o futuro. (Gastellu, 1979)

Entre os Agni, a unidade de acumulação não se diferencia na essência das unidades de produção e consumo na célula doméstica. Os produtos das atividades agrícolas perenes são vendidos pelo agricultor, diretamente ou por meio de cooperativas, ao exportador. Os ganhos decorrentes das vendas são acumulados e administrados pelo agricultor, que utiliza o necessário para o pagamento dos trabalhadores estrangeiros e para o pagamento dos dons de satisfação que ele oferece aos membros da família que participaram do trabalho agrícola, restando uma parte acumulada para a cobertura das demais despesas com a manutenção da célula familiar e da família extensa. (Gastellu, 1979)

Além da acumulação que ocorre com a venda dos produtos agrícolas, encontramos também a acumulação derivada das heranças que circulam dentro do grupo em conformidade às regras matrilineares que determinam, por exemplo, que o herdeiro deverá não apenas acumular, mas também conservar e aumentar a herança recebida.
Em Andé e Kouassikro encontramos dois diferentes grupos econômicos originários de acumulação fomentada pelas culturas de exportação. Embora ambos sejam produtores de cacau e café, a maior ou menor acumulação se justifica, entre outras coisas, pela extensão das terras cultiváveis e pela capacidade de bens destruídos em virtude dos diferentes eventos que atingem a família. A diferença na localidade se faz notar, sobretudo, pela ostentação das grandes casas que se espalham pela localidade como duplo daquelas erguidas em Abidjan. Outro elemento distintivo do poder de compra das diferentes famílias é a energia elétrica, que nas localidades rurais tem um preço excessivamente alto, o que aumenta as despesas mensais e não traz, segundo alguns, qualquer benefício significativo.

Nas sociedades Akan, assim como a maior parte das sociedades da Costa do Marfim, perfeitamente adaptadas ao sistema matrimonial poligâmico, os bens de cada esposa são separados dos bens dos maridos e das demais esposas, inclusive para evitar problemas entre os bens de cada uma delas na eventual dissolução de uma das uniões pactuadas pela poligamia.

\section{Sucessão e Herança}

Para os Agni, a criança é ao mesmo tempo um ser próximo do preexistente e das personagens primordiais da criação, como é apresentado nos mitos e nas diferentes ações decorrentes de situações específicas do nascimento. A criança ao nascer é a grande representação do ser natural justamente por ser a manifestação da carga de influências vitais que exercem os ancestrais, os elementais e o próprio ser criador no mundo dos homens. 0 nascimento reveste-se do mesmo potencial que tem a morte de um velho enquanto elemento de comunicação entre os dois diferentes mundos, o dos vivos e o dos mortos, sendo por isso reconhecidamente uma morte cósmica.

Os reinos e as crianças são assimilados às sementes, como sugere o historiador Djibril Niane em sua obra "Sundjata, ou a epopéia mandinga". As sementes representam a vida, assim como as crianças são a semente dos homens, representam a eternidade. Aqueles que não produzem sementes não merecem ser lembrados pela coletividade. Por isso a infertilidade se configura como problema crucial para as sociedades negro-africanas, acumuladoras de homens, por ser o 
exemplo máximo, juntamente com as práticas de bruxaria antropofágica, de ruptura com os códigos da dádiva. A criança revela a energia vital criadora do grupo de linhagem.

A herança, conceito segundo o qual os bens materiais e humanos do defunto devem ser atribuídos a uma outra pessoa da família com a finalidade de garantir a continuidade da vida sobre a terra, é atualmente fonte de algumas controvérsias na Costa do Marfim.

Embora possa parecer que a questão maior seja saber com quem deve ficar a herança (os bens materiais: dinheiro, ouro, imóveis, plantações de cacau e café etc.), se com os filhos, os irmãos ou os sobrinhos do falecido, ela nada mais é do que uma questão secundária. A primeira coisa a considerar é que entre os Agni o problema da herança fundamenta-se num conjunto de leis tradicionistas fundadas na matrilinearidade, na descendência e na própria idéia que têm os Agni a respeito da morte.

Assim, embora todas as pessoas possam produzir bens, as discussões sobre a herança excluem todos aqueles que não tenham produzido filhos ou que não tenham filhos vivos, muito embora os filhos não tenham quase nada a ver com as questões da herança, já que as leis ancestrais consideram apenas a família nuclear como legítima herdeira. Essa medida explicita bem o caráter da sociedade matrilinear e as obrigações que cada indivíduo tem para com um de seus objetivos maiores: acumular pessoas.

Isso justifica o fato de que somente aqueles que morrem deixando descendentes tenham direito a um herdeiro.

A obrigatoriedade da descendência revela a necessidade de que todos os indivíduos contribuam para a perpetuação biológica do grupo. Aquele que faz uma criança faz aumentar o capital social e humano da comunidade. Aquele que não faz uma criança contribui para a infertilidade e o desaparecimento do grupo. Aquele que tem um filho permanece na comunida- de, por meio dos ritos funerários, da preservação de seu nome e da perpetuação de seus atos.

Entre os Agni, a competência para definir e designar aquele que receberá a herança é das mulheres mais velhas da família do morto, sobretudo suas irmãs uterinas. Embora sejam elas as legítimas conhecedoras do caráter dos candidatos à herança, a sucessão é sempre muito tumultuada, uma vez que elas poderão jogar com argumentos que descredenciem alguns dos candidatos em benefício de seus próprios filhos, por exemplo.

Segundo o costume, o principal beneficiado pela herança deve ser o irmão uterino do falecido, segundo uma ordem de idade e de idoneidade. Naqueles casos em que o falecido não tem irmãos, em que o herdeiro principal tem algum impedimento (graves doenças), comportamento anti-social (alcoolismo etc.) ou não aceita a herança, ela passará então ao filho mais velho da irmã mais velha do falecido. Por isso, afirmam os Agni em um provérbio que trata da transmissão de herança: "quando a cabeça está presente, o joelho não usa o chapéu”. A cabeça é o irmão do falecido e o joelho, o filho de uma das suas irmãs germânicas ou uterinas.

Ser herdeiro implica num compromisso social com os diferentes atores sociais na preservação da memória do falecido. O herdeiro deve substituir dignamente o falecido, ocupando-se dos bens humanos e materiais por ele deixados sobre a Terra, inclusive casando-se com a sua esposa (levirato) ${ }^{5}$, quando a conveniência assim determinar ou permitir. Nenhum entrave pode ser colocado para evitar que o casamento ocorra, salvo se a mulher já for muito velha para procriar, ou mesmo se ela for mais velha do que o próprio herdeiro, estiver doente ou tiver comportamentos considerados socialmente negativos.

O herdeiro não se torna proprietário, mas sim depositário dos bens deixados pelo falecido. Assim será sua tarefa, além de zelar pelos bens, fazer também com que eles aumentem.

\footnotetext{
5 O levirato, instituição presente na organização social dos Agni Morofoé, possui estreitas ligações com a poligamia, a herança tradicionista, a matrilinearidade, a sucessão e a solidariedade, além de envolver a própria noção de pessoa, já que o herdeiro, ao assumir a herança do morto, confunde-se com ele mesmo e por isso deve assumir a responsabilidade por seus filhos e também, quase sempre, por sua mulher. Com o levirato, um dos irmãos assume a mulher do irmão mais velho falecido. Ao assumir a esposa, o irmão assume também a responsabilidade pelas crianças, a responsabilidade formal pela educação e o pleno desenvolvimento delas. 0 herdeiro também poderá recusar a mulher, assumindo tão somente as crianças e os bens, desde que apresente razões aceitáveis pela comunidade. Normalmente isso ocorre quando a mulher já está velha. A mulher também poderá se negar a aceitar o herdeiro como seu marido, o que normalmente é resolvido pela família, não havendo grandes problemas.
} 
Já a forma moderna de herança entre os Agni Morofoé é exemplo das influências da ocidentalização e das leis anteriormente citadas. A nosso ver, a adoção de tal modelo ajuda a romper os laços de solidariedade e o indivíduo passa a interagir com um grupo muito restrito e pequeno se comparado com o grande grupo formado pela família extensa. A adoção das leis modernas interfere inclusive nas relações de poder, uma vez que o herdeiro é conhecido antecipadamente.

Assim, como no caso dos casamentos, também no caso das heranças, no embate entre as leis tradicionais e modernas, surgem novas e interessantes dinâmicas revelando a força dos valores tradicionistas.

Inúmeros são os casos entre os Agni em que a herança é transmitida primeiramente aos herdeiros reconhecidos pela lei moderna que, por sua vez, em obediência às leis ancestrais, a transfere aos herdeiros tradicionistas, evitando assim a cólera dos traídos e tudo o que dela decorre ou possa decorrer.

\section{7 de Março de 2002, um Baobá Tombou}

Naquele dia, o jornal "Fraternité-Matin" trouxe estampado em sua primeira página, seguindo as regras tradicionais quando do aviso da morte de um grande dignitário, a triste manchete: "um baobá tombou".

O baobá ao qual se referia o jornal era o antropólogo e professor da Universidade de Cocody, Georges Niangoran-Bouah, conhecido por suas obras dedicadas ao universo dos pesos de pesar ouro e aos tambores de fala Akan. Nos dias seguintes pudemos acompanhar um dos mais ricos debates envolvendo duas famílias Akan pela disputa do direito ao corpo e aos funerais. O debate em questão envolveu a família materna (Abouré) e a família paterna (Abé) de Niangoran-Bouah.

Acompanhando a disputa, o jornal "FraternitéMatin” de 19 de maio de 2002 resumiu o problema nos seguintes termos: "O desaparecimento lamentável de um grande intelectual como era Georges NiangoranBouah faz com que nos apercebamos tristemente que nossas tradições não têm apenas valores positivos, mas que são também fontes inesgotáveis de frustrações, chantagens, discussões nocivas e objetos cruéis de divisões, de egoísmos históricos e impedimentos.

Na tradição Abouré de Moussou (matrilinear), o homem pertence à mãe; a mãe que o transportou durante nove meses, acompanhou seus primeiros passos, (...)". (Anoma-Kanie, 2002, p.26)

Como o embaixador Anoma-Kanie mesmo reconhecia, os Abé de Agboville (aldeia da família paterna de Niangoran-Bouah), que também pertencem ao grupo Akan, argumentavam que, segundo a mesma tradição matrilinear à qual recorriam os Abouré na defesa de que o corpo fosse sepultado em Moussou (aldeia da família materna de Niangoran-Bouah), "o corpo da criança e sua carne pertencem à linhagem de sua mãe, enquanto seus ossos pertencem ao reinado de seu pai", o que significa dizer que seu pai detém o privilégio de indicar a sua última morada e seu destino final, além de realizar os funerais.

O problema era muito simples para quase todos os marfinenses e a solução passava pela aplicação das leis costumeiras, como sugere uma canção de Koo Nimo intitulada "obi awu a, abi nna - Onipa nkrabea / la veillée des morts chez les Akan - Le destin de l'homme":

"O balanço sobe e desce...

Assim também é o destino do ser humano

Aee Aee Aee Aee Aee...

Ele vem à terra, então ele parte novamente para outro lugar.

Os Akan acreditam que

Deus dá a todo ser humano sua "alma" e seu "sopro de vida".

Eles acreditam que o pai de uma criança lhe transmite seu "espírito", para fortalecê-la - isto que os velhos chamam ntoro.

A mãe recebe a criança em suas entranhas e lhe transmite seu sangue; passados nove meses, nada lhe impede de emergir à vida.

É considerado que o ser nasceu vivo, ele é dotado de um Kra, habitando a terra, ele é um ser de carne e de sangue, dotado de uma língua e de um queixo, ser de palavra.

A canção de Koo Nimo refere-se, por um lado, ao destino pendular dos homens, o movimento cíclico na sua relação vida-morte-vida e, por outro, à própria noção de elementos constitutivos herdados dos ancestrais através do casal pai e mãe.

Assim, o ser humano é para os Akan um ser complexo, constituído por diversos elementos que formam um todo e o ligam no tempo e no espaço aos seus ancestrais maternos e paternos. 
Segundo a canção de Koo Nimo, a mãe transmite ao filho o seu sangue (mogya), ato que o liga à sua família uterina, e o pai, a força do duplo, que na canção aparece sob o nome de ntoro (espírito).

Embora existam controvérsias sobre os elementos constitutivos doados pela mãe e pelo pai para a formação do novo ser, é importante destacar a idéia que tem os Akan em geral e os Agni em particular, de que na formação da criança concorrem elementos vitais provenientes dos dois genitores, mas de forma diferenciada e definidora do pertencimento social e ancestral.

Assim, enquanto os Abé defendiam que NiangoranBouah fosse sepultado em Agboville, os Abouré defendiam que o sepultamento ocorresse em Moussou, localidade onde inclusive Niangoran fez seus estudos primários e fixou residência.

O embaixador Anoma-Kanie após fornecer dados sobre a questão da herança e dos direitos, com apelos direcionados ao que ele mesmo chamou de vida moderna, considera inadmissível a atitude dos dois grupos que, segundo ele, em vez de considerarem Niangoran-Bouah como uma herança de valor cultural mundial, apenas consideravam o oportunismo de interesses sobre a herança material.

Nada sabemos sobre como a questão foi resolvida no fórum privativo das duas famílias, sabemos apenas que, em abril de 2003, 13 meses depois do seu falecimento, a família materna realizou os funerais tradicionais e o corpo de Niangoran-Bouah foi sepultado no cemitério de Moussou, sua localidade uterina.

O debate em torno dos funerais de NiangoranBouah são reveladores das importantes questões colocadas para as sociedades Akan (matrilineares e patrilocais) e do quanto essas sociedades se movimentam segundo as tradições ancestrais, sempre que necessário, na garantia dos direitos costumeiros, e reforçam o papel das famílias extensas e dos valores civilizatórios Akan-Agni Morofoé (família, força vital, poder, ancestralidade, morte).

Por outro lado, o evento reabria as discussões ainda não esgotadas sobre o papel e a importância das instituições tradicionais na Costa do Marfim no que diz respeito à família extensa, considerada por muitos como um entrave no processo de modernização do país.

O hábito que têm alguns grupos da constelação Akan, sobretudo os Baoulé, de apresentar um pedido formal de desculpas ao chefe da localidade pela perda de um de seus membros, reconhecendo que o chefe é por assim dizer o proprietário de todos os homens que estão sob sua guarda, bem revela o sentido social da perda. Nesse sentido, o pedido de desculpas é uma forma de admissão de culpa da família que não conseguiu evitar que um dos seus viesse a falecer ou ainda evitar que a interferência maléfica de agentes sociais como o Bayafoé, por exemplo, tirasse uma das vidas, o bem mais precioso.

E como existe uma profunda relação entre herança e funeral, aqueles que morrem sem haver contribuído com a sociedade dando-lhe novos homens não terão direito a herdeiro e também não terão direito aos funerais Agni.

Retornar à localidade na ocorrência do falecimento de alguém da família materna ou paterna também é uma obrigação entre os Agni. Todos, exceto as mulheres grávidas e os doentes, devem comparecer e participar das cerimônias funerárias, inclusive ajudando nas despesas com a emissão de dons funerários.

O envio de dinheiro, panos, alimentos, bebidas ou animais para os sacrifícios, para dar de comer à família enlutada e para os estrangeiros convidados, estabelece um circuito de obrigações recíprocas entre as famílias e os aliados dentro da localidade. Os dons funerários talvez sejam os mais importantes, já que é por meio deles que os outros dons são possíveis. Os dons funerários estabelecem pactos entre as pessoas e a quebra de circuito pode ser penosa a qualquer um dos envolvidos. Percebemos nas nossas entrevistas que as famílias que trocam nos funerais são as mesmas que trocam em outros momentos, como o da doença.

A relação de solidariedade entre os moradores da localidade, sobretudo os membros de uma mesma família, pode ser observada na cerimônia intitulada N'Zie, que se constitui num momento de contribuição financeira comunitária. Em Andé, por meio do N’Zie, todas as pessoas com mais de 18 anos que tenham boa capacidade física e moral são chamadas a contribuir com pequenas somas, $100 \mathrm{~F}$ para os homens e $25 \mathrm{~F}$ para as mulheres. Essa é uma cerimônia pública que ocorre no mesmo local em que o corpo do morto se encontra exposto e onde todos aqueles que desejam contribuir o farão sob os olhos atentos da comunidade presente. Após a coleta, o chefe de cerimônias tornará público o valor arrecadado e o entregará à família do morto para ajudar nas despesas decorrentes do fune- 
ral (caixão, bebidas etc.), mas também para ajudar a esposa do falecido e seus filhos.

\section{E a Vida Continua...}

Se, como afirmou Alain Marie "na Costa do Marfim, nem a mundialização nem o liberalismo são abstrações teóricas" (Marie, 2002, p.207), o mesmo vale para a solidariedade. Ela existe de fato e atende a regras determinadas. Isso porque na África negra, embora seja o status social do indivíduo de uma comunidade que determina os direitos e as obrigações dele para com o grupo de produção e do grupo de produção para com ele, a solidariedade, embora ocorra individualmente, é a materialização de um pacto estabelecido entre os membros de uma família, entre algumas famílias e mesmo entre diferentes grupos étnicos. Nesse sentido, a solidariedade na África negra não deve ser entendida apenas como o pacto entre indivíduos, mas sim entre grupos de pessoas.

A AIDS faz aparecer todos os limites dessa rede que responde a regras fortemente codificadas (Hassoun, 1997) e que tem um papel importante na materialização da solidariedade frente à epidemia, seja ela no apoio psicológico e moral, nos auxílios financeiros ou mesmo na adoção das crianças da família cujos pais morreram vítimas da AIDS.

Nossa pesquisa procurou detectar quais eram os indivíduos mais solicitados nos momentos de real necessidade, e mais especificamente nos momentos de doença. Quais os tipos de ajuda solicitada, qual o tipo de ajuda oferecida, exigências etc. Pelo que pudemos constatar, enquanto a ajuda moral tem os amigos como elemento central, a ajuda financeira quase sempre fica restrita ao grupo familiar e se manifesta de diferentes maneiras. No caso das mulheres, a ajuda financeira permanente é dada por seu marido e a ajuda esporádica, por seu pai ou por um de seus irmãos. No caso de mulheres viúvas ou separadas, a ajuda esporádica ou permanente quase sempre é dada por um de seus irmãos. As mulheres viúvas podem ainda recorrer ao herdeiro de seu marido.

As solidariedades familiar e comunitária estão sendo testadas na velocidade com que avança a epidemia. As redes de solidariedade parecem não ter sido preparadas para responder a uma realidade cuja duração parece ser tão longa. 0 que se justifica pelo me- do da própria epidemia, pela situação econômica do país e também pela saturação das diferentes formas de solidariedade que já não conseguem atender às necessidades dos membros do grupo. Normalmente, as redes de solidariedade das quais participa o indivíduo ultrapassam os limites da célula familiar. No entanto, diante das dificuldades econômicas, é primeiramente dentro da célula familiar que o indivíduo buscará recursos para a solução do problema. Esgotadas as fontes da rede da célula familiar, o indivíduo lançará mão das redes externas. Ocorre que a rede externa, assim como a rede interna, diante da epidemia encontra-se saturada, sobretudo porque deixa de existir a possibilidade de reciprocidade, sobre a qual se apóia o funcionamento das redes de solidariedade. 0 indivíduo tira da massa econômica social e não consegue restituir. Além disso, gera um excedente de consumo, uma vez que seus filhos passam a ser alimentados por outros membros da família. Ou seja, embora ele faça parte do grupo de produção, não produz, apenas consome e ao consumir nada dá em troca à sua comunidade.

As redes de solidariedade familiar que funcionam graças aos recursos produzidos por seus membros, atribuindo a cada um direitos e obrigações segundo seu status social, encontram na AIDS um de seus maiores desafios. O status social de um determinado indivíduo pode determinar se ele pertence ao grupo que acumula e distribui ou ao grupo que recebe.

Quando alguém que pertence ao grupo que acumula e distribui adoece em virtude da AIDS, suas reservas são consumidas e ele passa então a depender de outro grupo de acumulação e distribuição, e o seu status social torna-se um dos maiores obstáculos, uma vez que ele se sente humilhado ao ter de depender de outros. Por outro lado, a menos que ele confesse suas necessidades, nenhum grupo de acumulação/ distribuição o ajudará. A AIDS, em muitos casos, impede a manutenção do status social da pessoa doente, além de fragilizar o status familiar em função das diferentes interpretações que ela sugere.

Em Ande, essa relação entre os grupos de produção, acumulação e consumo não envolve apenas os membros das famílias que habitam a localidade, mas também os seus membros considerados homens fortes pelo sucesso alcançado como funcionários do governo ou das empresas privadas.

O status que decorre da posição social que cada 
um ocupa dentro do grupo é reconhecido por todos e será usado no momento adequado, normalmente nas doenças, nos funerais ou nos casamentos, quando cada um é chamado a participar oferecendo seus dons.

A família e a comunidade envolvida esperam que todos ofereçam dons significativos e à altura do status publicamente reconhecido. O indivíduo, por sua vez, apresentará os dons necessários à manutenção de seu status perante a família/ comunidade.

Frente a um sistema de saúde altamente deficitário para o atendimento dos doentes, resta a solidariedade da família e dos amigos, importantes em todos os momentos da vida do doente. E não somente o atendimento econômico, mas também o atendimento social e psicológico.

Mas a AIDS continua a criar um verdadeiro desequilíbrio entre a capacidade de dar da família e dos membros externos e a própria demanda criada em função do rápido avanço da epidemia sobre as diversas áreas socioespaciais urbanas e rurais, sobretudo porque os mais atingidos, como já afirmamos, são justamente os jovens e os adultos, indivíduos mais produtivos economicamente e dos quais o grupo é mais dependente nas prestações de bens.

Os efeitos da perda desses indivíduos mais produtivos logo podem ser percebidos na relação de consumo do grupo familiar. As crianças deixam de freqüentar a escola para ajudar os parentes mais velhos nas atividades agrícolas ou em outras atividades que possam ajudar a suprir a falta econômica que faz o morto. E como notadamente a família não é formada apenas pela estrutura nuclear e sim por um conjunto de pessoas a ela associada, todos passam a sentir as necessidades causadas pela morte prematura.

A AIDS acelera o movimento inverso de transferência de crianças, da cidade para as zonas rurais. É assim que as mulheres, antes de cessarem suas atividades profissionais ou antes de terem seus recursos diminuídos até o total desaparecimento com a sua morte, confiam seus filhos aos parentes da família extensa fixados na zona rural. Assim, a partida das crianças, a redução do número de pessoas acolhidas e as mortes ocasionadas pela AIDS provocam uma profunda desestruturação na célula doméstica. (Hassoun, 1997)

Dessa forma, ao mesmo tempo em que, como afirmaram Delcroix e Guillaume (1997), a AIDS provoca uma alteração do modelo nuclear para o modelo monoparental, o envio das crianças para as localidades rurais gera um peso suplementar para a família que a abriga e que passa a responder às necessidades econômicas e alimentares com o grupo de consumo ampliado. ${ }^{6}$

Embora o abandono possa acontecer na família nuclear, raramente ouviremos falar de abandono pela família extensa dos seus membros doentes de AIDS, e caso aconteça precisaremos analisar o caso para de fato sabermos se o abandono se deu em função da AIDS ou de qualquer outro problema. Esta idéia é reforçada pelos trabalhos desenvolvidos por Koegh (1988)7 em Kigali, Didier Blibolo (1991), em Abidjan e Maxime Ankrah (1993) e em Kampala.

Normalmente os programas relacionados aos impactos do HIV/AIDS sobre a solidariedade tradicionista ou moderna não fazem mais do que discutir o problema dos órfãos, sem considerar, por exemplo, o problema das viúvas e da própria família dependente do doente. Além disso, o impacto não ocorre apenas com a morte, mas bem antes dela, nas infindáveis visitas feitas ao posto de saúde, aos hospitais universitários, aos centros de tratamento e aos terapeutas tradicionistas.

Embora acreditemos na capacidade ótima das sociedades negro-africanas de transformarem em fases e não em totalidades os impactos decorrentes de processos desestabilizadores e desestruturadores, vemos na epidemia do HIV/AIDS um real desafio para a vida no continente em sua plenitude. E a vida plena, traduzida pela palavra "Mendilé" em alguns grupos Akan, significa literalmente "comer o mundo", apropriar-se dos recursos exteriores que asseguram e fazem prosperar a existência. Para os Akan, a vida, além

6 Pelo que notamos nas aldeias Ande e Kouassikro, a circulação de crianças no sentido espaço rural - espaço urbano é muito comum e justificada sobretudo pela necessidade de continuidade dos estudos. O que a AIDS acaba gerando, pelo menos em Abidjan, é um movimento inverso espaço urbano - espaço rural com sérias conseqüências para a célula de produção, que vê a célula de consumo ampliada, e para a criança, que normalmente tem que abandonar a escola.

7 KOEGH, P. An evaluation of the need for social service of HIV positive women enrolled in a cohort study in Kigali, Rwanda. Projet San Francisco, 1988 
de um valor em si mesma, é também o recurso para outros valores e a finalidade e a razão de ser de todas as atividades ligadas ao conhecimento e à economia, justificando, por exemplo, a importância que tem a sexualidade, a procriação e a maternidade, seus atores (homem-mulher) e instituições como o casamento e a poligamia. Por isso, afirma o provérbio Akan: “a criança é o remédio do homem contra a morte”.

\section{Referências}

ABITBOL, Eliette. La famille conjugale et le droit nouveau du mariage en Côte d'Ivoire. Journal of African Law, London, v. 10, n. 3, p. 141-163, autumn 1966.

AMIM, Samir. Le développement du capitalisme en Côte d'Ivoire. Paris: Minuit, 1967.

AMSELLE, Jean-Loup; M'BOKOLO, Elikia. Au coeur de l'ethnie, tribalisme et état en Afrique. Paris: Décourvete, 1999.

ANKRAH, Maxime. Aids and the social side of health. Social Science and Medicine, Londres, v. 32, n. 9, p. 967$980,1993$.

BAHA, Bi Youzan. Genre et developpement: analyse sectorielle de la situation socio-économique, politique et juridique de la femme en Côte d'Ivore. Revue Ivoirienne d'Anthropologie et de Sociologie, Abidjan, n. 2, 2001.

BARNETT, P.; BLAIKIE, P. Aids in Africa: its present an future impact. Londres: Belhaven, 1992.

BÉCHU, Natalie et al. Devenir socio-économique des enfants et familles afectes par le VIH/Sida dans les pays en developpement: le cas de la Côte d'Ivoire. Paris: Agence Nationale de Recherches sur le Sida, 1997.

BLIBOLO, Auguste Didier. La prise en charge psychosociale des séropositifs à Abidjan: mémoire de maîtrise de sociologie médicale. Abidjan: Université d'Abidjan, 1991.

D’ABY, F. J. Amon. Croyances religieuses et coutumes juridiques des Agni de la Côte d'Ivoire. Paris: Larose, 1960.

DELCROIX, Sylvie et al. Devenir socio-économique des enfants et familles afectes par le VIH/SIDA dans les pays en developpement: le cas de la Côte d'Ivoire. Paris: Agence Nationale de Recherches sur le SIDA, 1997.
ERNY, Pierre. L'enfant dans la pensée traditionelle de l'Afrique noire. Paris: Harmattan, 1990.

ESCHLIMAN, Jean-Paul. Les Agni devant la mort. Paris: Karthala, 1982.

FARMER, Paul. Aids and accusation: Haiti and the geography of blame. Berkeley: University of California, 1992.

FOLQUET, L. G. La situation juridique de la femme mariée dans le nouveau droit de la famille ivoirienne. Revue Juridique et Politique Indépendante et Coopération, Paris : Ediafric, p. 636-637, (4), 1974.

GASTELLU, Jean-Marc. Mais, où sont donc ces unités économiques que nos amis cherchent tant en Afrique? Abidjan: ORSTOM, 1979.

GUILLAUME, Agnès et al. Recompositions familiales et gestion économiques et sociale du sida dans des familles afectes en Côte d'ivoire. In : Annales du Colloque international «Sciences Sociales et SIDA en Afrique : Bilan et perspectives ", Dakar : CODESRIA, 1996, p.683-693.

HASSOUN, Judith. La solidarité familiale face au sida: résultats d'une enquête réalisée à Abidjan (Côte d'Ivoire) auprès de femmes malades du sida. Autrepart, Paris, n. 2, p. 105-122, 1997.

HOUPHOUËT-BOIGNY, Félix. Anthologie des discours 1946-1978. Abidjan: CEDA, 1978.

KANIE, Anoma-Kanie. La mort de Niangoran-Bouah, journal Fraternité Matin, Abidjan, 2002, p. 16.

KOBBEN, A. J. F. Le planteur noir. Paris: Institut Français d'Afrique Noire, 1956.

KOEGH, P. An evaluation of the need for social service of HIV positive women enrolled in a cohort study in Kigali, Rwanda. Projet San Francisco, 1988.

LAPLANTINE, François. Antropologia da doença. São Paulo: Martins Fontes, 1991.

LEITE, Fábio Rubens da Rocha. A questão ancestral: notas sobre ancestralidade e instituições ancestrais em sociedades africanas: loruba, Agni e Senufo. 1982. Tese - FFLCH da USP, 1982.

LEITE, Fábio Rubens da Rocha. Bruxos e magos. África, São Paulo, v. 14/15, n. 1, p. 69-8o, 1991/1992. 
LEITE, Fábio Rubens da Rocha A questão da palavra em sociedades negro-africanas. In: SANTOS, Juana Elbein dos (Org.). Democracia e diversidade humana: desafio contemporâneo. Salvador: SECNEB, 1992. p. 85-95.

LEITE, Fábio Rubens da Rocha Valores civilizatórios em sociedades negro-africanas: introdução aos estudos sobre África contemporânea. África, São Paulo, v. 18/19, n. 1, p. 103-118, 1995/1996.

MARIE, Alain. Une anthropo-logique communautaire à l'èpreuve de la mondialisation: de la relation de dette à la lutte sociale (l'exemple ivoirien). Cahier d'Études Africaines, Paris, v, 42, n. 2, p. 207-255, 2002.

NIANE, Djibril Tamsir. Sundjata, ou a epopéia mandinga. São Paulo: Ática, 1982.

SODRÉ, Muniz. O terreiro e a cidade: a formação social negro-brasileira. Petrópolis: Vozes, 1988.
STAVENHAGEN, Rodolfo. Las clases sociales en las sociedades agrárias. México, DF: Siglo XXI, 1970.

THOMAS, Louis-Vicent. Le pluralisme cohérent de la notion de personne en Afrique noire tradicionelle. In: Actes du Colloque International sur «La notion de personne en Afrique noire ». CNRS, Paris : L'Harmattan, 1993, p. 387-420.

TURNER, Victor. O processo ritual: estrutura e antiestrutura. Petrópolis: Vozes, 1998.

VIMARD, Patrice. Diversite des structures familiales en Cote d'voire: une approche a partir d'etudes de cas en milieu rural Akan. Abidjan: ORSTOM, 1987.

YENOU, H. et al. Sida et orphelins in la recherché en santé au service du développement. Abidjan: CEDA, 2001. 